\title{
Laparoscopic gastrectomy for stage II and III advanced gastric cancer: long-term follow-up data from a Western multicenter retrospective study
}

\author{
Umberto Bracale ${ }^{1}\left[\right.$ - Giovanni Merola ${ }^{1}$. Giusto Pignata ${ }^{2}$. Jacopo Andreuccetti ${ }^{3}$. Pasquale Dolce ${ }^{4}$. Luigi Boni ${ }^{5}$. \\ Elisa Cassinotti ${ }^{5}$. Stefano Olmi ${ }^{6}$. Matteo Uccelli ${ }^{6}$. Monica Gualtierotti ${ }^{7}$. Giovanni Ferrari ${ }^{7}$. Paolo De Martini ${ }^{7}$. \\ Miloš Bjelović ${ }^{8}$. Dragan Gunjić ${ }^{8}$. Vania Silvestri ${ }^{1}$ - Emanuele Pontecorvi ${ }^{1} \cdot$ Roberto Peltrini $^{1} \cdot$ Felice Pirozzi $^{9}$. \\ Diego Cuccurullo ${ }^{10} \cdot$ Antonio Sciuto $^{9} \cdot$ Francesco Corcione $^{1}$
}

Received: 17 September 2020 / Accepted: 7 April 2021 / Published online: 20 April 2021

(c) The Author(s) 2021

\begin{abstract}
Introduction There has been an increasing interest for the laparoscopic treatment of early gastric cancer, especially among Eastern surgeons. However, the oncological effectiveness of Laparoscopic Gastrectomy (LG) for Advanced Gastric Cancer (AGC) remains a subject of debate, especially in Western countries where limited reports have been published. The aim of this paper is to retrospectively analyze short- and long-term results of LG for AGC in a real-life Western practice.

Materials and methods All consecutive cases of LG with D2 lymphadenectomy for AGC performed from January 2005 to December 2019 at seven different surgical departments were analyzed retrospectively. The primary outcome was diseases-free survival (DFS). Secondary outcomes were overall survival (OS), number of retrieved lymph nodes, postoperative morbidity and conversion rate.

Results A total of 366 patients with stage II and III AGC underwent either total or subtotal LG. The mean number of harvested lymph nodes was $25 \pm 14$. The mean hospital stay was $13 \pm 10$ days and overall postoperative morbidity rate $27.32 \%$, with severe complications (grade $\geq$ III) accounting for $9.29 \%$. The median follow-up was $36 \pm 16$ months during which 90 deaths occurred, all due to disease progression. The DFS and OS probability was equal to 0.85 (95\% CI 0.81-0.89) and 0.94 (95\% CI 0.92-0.97) at 1 year, 0.62 (95\% CI 0.55-0.69) and 0.63 (95\% CI 0.56-0.71) at 5 years, respectively.

Conclusion Our study has led us to conclude that LG for AGC is feasible and safe in the general practice of Western institutions when performed by trained surgeons.
\end{abstract}

Keywords Laparoscopy $\cdot$ Laparoscopic gastrectomy $\cdot$ Advanced gastric cancer $\cdot$ Malignancy $\cdot$ Stomach

Umberto Bracale

umbertobracale@gmail.com

1 Department of General Surgery and Specialty, School of Medicine University, Federico II of Naples, Naples, Italy

2 Department of General Surgery II, Spedali Civili of Brescia, Brescia, Italy

3 Department of General and Mininvasive Surgery, San Camillo Hospital of Trento, Trento, Italy

4 Department of Public Health, Federico II University of Naples, Naples, Italy

5 Department of Surgery, Fondazione IRCCS Ca' Granda, Ospedale Maggiore Policlinico, University of Milan, Milan, Italy
6 Department of General and Oncologic Surgery, Centre of Advanced Laparoscopic Surgery, Centre of Bariatric Surgery, San Marco Hospital GSD, Zingonia, BG, Italy

7 Department of Minimally Invasive Oncologic Surgery, Niguarda Hospital, ASST Grande Ospedale Metropolitano Niguarda, Milan, Italy

8 Department for Minimally Invasive Upper Digestive Surgery, Hospital for Digestive Surgery, Clinical Center of Serbia, School of Medicine, University of Belgrade, Belgrade, Serbia

9 Department of General Surgery, Santa Maria Delle Grazie Hospital, Pozzuoli, NA, Italy

10 Department of General, Mini-Invasive and Robotic Surgery, Monaldi Hospital, Naples, NA, Italy 
Gastric cancer is the fifth most common malignancy and the third cause of cancer death worldwide [1]. There is a wide difference in terms of geographical prevalence, with most cases occurring in Japan, Korea and China [2]. Almost one million new cases were diagnosed globally in 2012, with more than 700,000 deaths. Of these, about 140,000 cases and more than 100,000 deaths occurred in Europe [3].

Standard gastrectomy is the main surgical procedure with curative intent for gastric cancer [4]. Since the first report of laparoscopic gastrectomy (LG) for cancer in 1994 [5], there has been an increasing interest, especially among the Eastern surgeons, for minimally invasive approach because of shortterm advantages over open surgery [6]. These benefits as well as the oncological safety of LG have been clearly demonstrated for early gastric cancer. On the other hand, despite the adequate short-term outcomes, the oncological effectiveness of laparoscopic surgery for advanced gastric cancer (AGC) remains a subject of debate [7]. Indeed, several studies demonstrated the safety, feasibility and oncological value of LG compared with open gastrectomy for AGC, but most of the data comes from Eastern high-volume referral centers [8-11]. On the contrary, limited reports from the Western institutions have been published since the first and only randomized study by Huscher et al. [12] back in 2005 .

The aim of this paper is to analyze short- and long-term results of LG for AGC in a real-life Western practice.

\section{Materials and methods}

The study was approved by independent ethics committee or institutional review board of each participating institution. All candidates involved in this study provided written informed consent to manage their data. Using a prospective database, all consecutive cases of laparoscopic either total (LTG) or subtotal (LSG) gastrectomy with D2 lymphadenectomy for AGC performed from January 2005 to December 2019 at seven different departments of surgery were analyzed retrospectively.

All procedures were performed by fully trained surgeons with extensive experience in surgical oncology as well as laparoscopy.

In order to obtain a quality control of the surgical procedures, non-edited videos of both LTG and LSG performed by each participant were reviewed by the study coordinator before inclusion. Tumor stages were updated according to the 8th edition of American Joint Committee on Cancer (AJCC) TNM staging system for gastric cancer [13], and only stage II and III AGC cases were analyzed.

Preoperative (age, sex, BMI, previous abdominal surgery, ASA score, neoadjuvant therapy), intraoperative (operative time, complications, conversion rate, lymphadenectomy, type of anastomosis), and postoperative short-term (return of bowel function, hospital stay, complications, reoperation and mortality rates, TNM stage [4], number of harvested and metastatic lymph nodes) and long-term (overall survival (OS), disease-free survival (DFS), recurrence rate) data were reviewed.

Thirty-day postoperative complications were graded according to the Clavien-Dindo classification [14]. Anastomotic leakage was evaluated in accordance with the definition and grading system of the UK Surgical Infection Study Group [15].

Preoperative staging included upper gastrointestinal endoscopy and abdominal and thoracic computed tomography (CT) while endoscopic ultrasonography was not routinely performed. Since 2011 neoadjuvant chemotherapy was performed in case of $\mathrm{cN}+$ or $\geq \mathrm{cT} 2$ tumor. All procedures started with a Diagnostic Laparoscopy (DL) in order to detect a possible carcinomatosis. Adjuvant chemotherapy was carried out for patients with stage $\geq$ IB [3]. Every patient was followed-up every 6 months during the first 2 years and annually thereafter according to the local protocols.

Locoregional recurrence was defined as recurred carcinoma of the remnant gastric pouch or at anastomosis site or within the lymphatic drainage area of the region of the primary tumor, confirmed by CT scan and/or pathological examination. Distant metastases were defined as recurrent tumors in the peritoneum, liver, non-regional lymph nodes, or outside the abdominal cavity such as lung, bones, etc.

The primary outcome was DFS. Secondary outcomes were OS, number of retrieved lymph nodes, postoperative morbidity and conversion rate.

\section{Neoadjuvant chemotherapy}

Neoadjuvant chemotherapy regimens consisted of a combination of Epirubicin-Cisplatin-5-fluorouracil-Folinic Acid (ECF, $50 \mathrm{mg} / \mathrm{m}^{2}$ epirubicin, $60 \mathrm{mg} / \mathrm{m}^{2}$ cisplatin, and 5-FU administered either by continuous infusion $200 \mathrm{mg} /$ $\mathrm{m}^{2} /$ day per 7 days via a CVC, administered every 3 weeks) or 5-fluorouracil-Folinic Acid-Oxaliplatin-Docetaxel (FLOT, docetaxel $\left(60 \mathrm{mg} / \mathrm{m}^{2}\right)$, oxaliplatin $\left(85 \mathrm{mg} / \mathrm{m}^{2}\right)$, leucovorin $\left(200 \mathrm{mg} / \mathrm{m}^{2}\right)$, and 5-fluorouracil $\left(2600 \mathrm{mg} / \mathrm{m}^{2}\right.$ as a $24 \mathrm{~h}$ infusion), all given on day 1 and administered every 2 weeks).

\section{Statistical analysis}

Data are presented as median (I quartile-Q1; III quartile-Q3) or mean \pm standard deviation (SD) for quantitative variables as appropriate and as number of patients (\%) for qualitative variables.

Actuarial OS was calculated as the time from surgery to death using Kaplan-Meier methods. Differences between curves were tested using the Log-Rank test. Univariate and 
multivariate Cox proportional hazard regression analysis was performed to estimate the hazard ratios for OR.

All statistical analyses were performed using R 3.6.0 software. Survival analysis was performed using survival package, version 2.44-1.1. Statistical significance was predetermined as $p<0.05$. All tests were two-tailed and statistical significance was set at an $\alpha$ level of 0.05 .

\section{Surgical technique}

\section{Laparoscopic subtotal gastrectomy (LSG)}

Four trocars were placed in the upper abdomen. Following abdominal exploration and omentectomy, lymph node dissection was performed including D1 (stations 1-7) $+8 \mathrm{a}$ (common hepatic artery), 9 (celiac), 11p (proximal splenic artery) and 12a (anterior hepato-duodenal ligament) stations [16]. The stomach was sectioned using a linear stapler with the aim to achieve a proximal margin of $5 \mathrm{~cm}$. Either Rouxen-Y or Billroth II anastomosis was performed. A side-toside gastro-jejunal anastomosis was performed with a linear stapler.

\section{Laparoscopic total gastrectomy (LTG)}

The technique was the same for LSG until section of the stomach [17, 18]. Lymph node dissection included also the $11 \mathrm{~d}$ (distal splenic artery) station. The gastroesophageal junction was sectioned using a linear stapler and then a Roux-en-Y reconstruction was always performed. Oesophago-jejunal anastomosis was performed using either a circular or a linear stapler (like Orringer) [19, 20].

\section{Results}

\section{Patients demographics, types of gastrectomy and pathologic features}

From January 2005 to December 2019, a total of 654 patients underwent either LTG or LSG at seven different surgical units. Three hundred and sixty-six patients were analyzed according to the inclusion criteria. Patient characteristics and pathologic features are reported in Table 1.

LSG and LTG were performed in $257(70.8 \%)$ and 109 (29.2\%) cases, respectively. D2 dissection was performed in $352(96.2 \%)$ cases, while D2 + dissection was performed in $14(3.8 \%)$ cases.

The mean operative time was $247.7 \pm 105.3 \mathrm{~min}$ and conversion rate $14.5 \%$ (53/366). Conversions were due to extensive adhesions ( 25 cases), accidental spleen injury ( 6 cases), bleeding (10 cases) and bulky tumors or cancers invading serosa or adjacent structures (12 cases). Intraoperative data are reported in Table 1.

The median number of harvested lymph nodes was $25 \pm 14$. Cancer pathologic stages were: IIA in $80(21.8 \%)$ patients, IIB in $64(17.5 \%)$ patients, IIIA in $126(34.4 \%)$ patients, IIIB in 77 (21\%) patients and IIIC in $19(5.1 \%)$ patients.

\section{Postoperative complications and treatment}

The mean length of hospital stay was $13 \pm 10$ days and overall postoperative morbidity rate was $27.32 \%(100 / 366)$ with severe complications (grade $\geq$ III) accounting for $9.29 \%$ (Table 1).

Grade IIIa complications included an esophago-jejunal leak and 7 cases of anastomotic bleeding, which were all managed endoscopically, while operative management was needed in 20 cases (grade IIIb) including anastomotic leakage ( 9 cases), duodenal stump leakage ( 4 cases), abdominal bleeding ( 5 cases), internal hernia ( 1 case) and transverse colon ischemia (1 case). We reported 3 grade V complications, accounting for a postoperative mortality of $0.81 \%$. Details about postoperative complications and their management are reported in Tables 1 and 2. Logistic binary regression for complications adjusted for other effects (Table 3) showed at univariate analysis a statistically significant difference in patients who underwent neoadjuvant therapy (OR $2.15 ; p$ value 0.03 ). This difference was confirmed at multivariate analysis (OR 2.17; $p$ value 0.04 ).

\section{Survival and recurrence}

The median follow-up was $36 \pm 16$ months (range 1-80 months) during which 90 deaths occurred, all due to disease progression. Kaplan-Meier OS curve is presented in Fig. 1a. The OS probability was equal to 0.94 (95\% CI $0.92-0.97)$ at 1 year and 0.63 (95\% CI $0.56-0.71)$ at 5 years. Kaplan-Meier OS curves (Fig. 1b, c) were also reported stratifying for procedure (LSG vs. LTG) and stage (II vs. III). The OS probability for stage II was 0.97 (95\% CI 0.94-0.99) at 1 year and $0.73(95 \%$ CI $0.63-0.85)$ at 5 years. The OS probability for stage III was $0.92(95 \%$ CI $0.89-0.96)$ at 1 year and 0.56 (95\% CI $0.46-0.68)$ at 5 years. The corresponding log-rank tests for LSG vs. LTG and stage II vs. stage III demonstrated a non-significant $(p=0.15)$ and a significant difference $(p=0.0006)$, respectively. However, at multivariate Cox regressions, both differences were found statistically non-significant. Table 5 shows the results for univariate and multivariate Cox regression analysis for OS. Except for metastatic nodes ( $\mathrm{aHR}=1.06, p<0.009$ ), all the other variables were not significantly associated to OS at multivariate analysis (Table 4). 
Table 1 Biometric and pathological features, intra- and postoperative data

\begin{tabular}{|c|c|c|c|}
\hline & Patients $(n=366)$ & $\begin{array}{l}\text { Laparoscopic total gastrec- } \\
\text { tomy }(n=109)\end{array}$ & $\begin{array}{l}\text { Laparoscopic subtotal } \\
\text { gastrectomy }(n=257)\end{array}$ \\
\hline $\operatorname{Sex}(M / F)$ & $204 / 162$ & $73 / 36$ & $131 / 126$ \\
\hline Age $($ mean $\pm S D)$ years & $68.4 \pm 11.6$ & $66.1 \pm 11.3$ & $69.4 \pm 11.7$ \\
\hline $\mathrm{BMI}($ mean $\pm \mathrm{SD}) \mathrm{Kg} / \mathrm{m}^{2}$ & $24.8 \pm 4.1$ & $24.5 \pm 3.6$ & $24.9 \pm 4.3$ \\
\hline \multicolumn{4}{|l|}{ Previous abdominal surgery } \\
\hline Cholecystectomy & $18(5 \%)$ & 6 & 12 \\
\hline Appendectomy & $24(6.6 \%)$ & 13 & 11 \\
\hline Hysterectomy & $9(2.5 \%)$ & 5 & 4 \\
\hline Left colectomy & $4(1.1 \%)$ & 1 & 3 \\
\hline Right colectomy & $2(1 \%)$ & 1 & 1 \\
\hline \multicolumn{4}{|l|}{ ASA } \\
\hline I & $42(11.5 \%)$ & 17 & 25 \\
\hline II & $212(57.9 \%)$ & 64 & 148 \\
\hline III & $111(30.3 \%)$ & 27 & 84 \\
\hline IV & 1 & 1 & 0 \\
\hline \multicolumn{4}{|l|}{ Stage $^{\mathrm{a}}$} \\
\hline IIa & $80(21.8 \%)$ & 25 & 55 \\
\hline IIb & $64(17.5 \%)$ & 19 & 45 \\
\hline IIIa & $126(34.4 \%)$ & 45 & 81 \\
\hline IIIb & $77(21 \%)$ & 48 & 29 \\
\hline IIIc & $19(5.1 \%)$ & 7 & 12 \\
\hline Neoadjuvant therapy & $97(26 \%)$ & 30 & 67 \\
\hline OrVil/Orringer anastomosis & & $3 / 106$ & \\
\hline Roux-en-Y/Billroth II & $342 / 24$ & $109 / 0$ & $233 / 24$ \\
\hline Operative time $($ mean $\pm S D) \min$ & $247.7 \pm 105.3$ & $273.8 \pm 114.9$ & $236.6 \pm 99.1$ \\
\hline Nodes harvested (median $\pm I Q R)$ & $25 \pm 14$ & $25 \pm 10$ & $27 \pm 11$ \\
\hline Metastatic nodes (median \pm IQR) & $1 \pm 5$ & $3 \pm 4$ & $2 \pm 3$ \\
\hline Intraoperative complications $n(\%)$ & $21(5.7 \%)$ & $11(3 \%)$ & $10(2.7 \%)$ \\
\hline Conversion $n(\%)$ & $53(14.5 \%)$ & $32(8.7 \%)$ & $21(5.7 \%)$ \\
\hline \multicolumn{4}{|l|}{ Lymphadenectomy $n(\%)$} \\
\hline D2 & $352(96.17 \%)$ & 103 & 249 \\
\hline $\mathrm{D} 2+$ & $14(3.82 \%)$ & 6 & 8 \\
\hline Overall postoperative complications $n(\%)$ & $100(27.3 \%)$ & $32(8.7 \%)$ & $68(18.57 \%)$ \\
\hline \multicolumn{4}{|l|}{ Postoperative complications } \\
\hline II & 66 & 18 & 48 \\
\hline IIIa & 8 & 3 & 5 \\
\hline IIIb & 20 & 10 & 10 \\
\hline IV & 3 & 1 & 2 \\
\hline $\mathrm{V}$ & 3 & 0 & 3 \\
\hline Bowel recovery (mean \pm SD) days & $3.6 \pm 2.3$ & $3.9 \pm 2.3$ & $2.4 \pm 2.3$ \\
\hline Length of stay (median $\pm \mathrm{IQR}$ ) days & $13 \pm 10$ & $15 \pm 12$ & $12 \pm 8$ \\
\hline Death related to disease progression $n(\%)$ & $90(24.6 \%)$ & $35(9.58 \%)$ & $55(15.02 \%)$ \\
\hline Follow-up (median $\pm \mathrm{IQR}$; range) months & $36 \pm 16$ (range $1-80$ months) & & \\
\hline
\end{tabular}

$I Q R$ interquartile range, $B M I$ body mass index, ASA American Society of Anesthesiologists

${ }^{\mathrm{a}} \mathrm{AJCC}$ TNM staging, 8th edition

The overall recurrence rate was $28.6 \%$ (105/366). There were $32 / 366$ (8.7\%) cases of locoregional recurrence, including 15 (4\%) of regional lymph node involvement, 10 (2.7\%) in the remnant stomach and $7(2 \%)$ at the anastomotic site. Distant metastases were found in 60/366 (16.4\%) cases at the following sites: peritoneum ( 26 cases, $7.1 \%$ ), liver ( 21 cases, 
Table 2 Postoperative complications and their treatment after laparoscopic gastrectomy

\begin{tabular}{lcl}
\hline Postoperative complication & $n(\%)$ & Treatment \\
\hline Total & $100(27.32 \%)$ & \\
Ileuss & $13(3.55 \%)$ & 13 nasogastric tube re-positioning \\
Urinary infection & $15(4.09 \%)$ & 15 antibiotic therapy \\
Wound infection & $16(4.37 \%)$ & 16 antibiotic therapy \\
Bleeding & $15(4.09 \%)$ & 5 laparoscopic hemostasis \\
& $15(4.09 \%)$ & 10 blood transfusion \\
Lung morbidity & $4(1.09 \%)$ & 3 pulmonary embolisms needed intensive care unit therapy \\
& $3(0.81 \%)$ & 12 pulmonary infections needed antibiotic therapy \\
Esophago-jejunal bleeding & $8(2.18 \%)$ & All solved with endoscopic hemostasis \\
Gastro-jejunal bleeding & & 4 laparoscopic anastomotic re-do \\
Esophago-jejunal leakage & 1 endoscopic stent placement \\
& $1(0.27 \%)$ & 3 open anastomotic re-do \\
Gastro-jejunal leakage & $1(0.27 \%)$ & 1 laparoscopic anastomotic re-do \\
Jejuno-jejunal-leakage & $4(1.09 \%)$ & 1 laparoscopic anastomotic re-do \\
Duodenal leakage & $1(0.27 \%)$ & 2 laparoscopic peritoneal toilettes, suture of duodenum and drainage \\
& $1(0.27 \%)$ & 2 open peritoneal toilettes, suture of duodenum and drainage \\
Internal hernia & $3(0.82 \%)$ & 1 laparoscopic internal hernia reduction and mesentery defect closure \\
Transverse colon ischemia & 1 open transverse colon resection \\
Postoperative mortality & All due to heart failure \\
\hline
\end{tabular}

$5.7 \%$ ), other organs (8 cases, $2.1 \%$ ), non-regional lymph nodes ( 5 cases, $1.4 \%$ ). Recurrence at both locoregional and distant sites occurred in 13/366 (3.5\%) cases.

DFS probability was 0.85 (95\% CI $0.81-0.89)$ at 1 year and 0.62 (95\% CI $0.55-0.69)$ at 5 years (Fig. 2a). Kaplan-Meier DFS curves (Fig. 2b, c) were also reported stratifying for procedure (LSG vs. LTG) and stage (II vs. III) (Table 5).

\section{Discussion}

Radical gastrectomy still represents the treatment of choice for gastric cancer. In case of early gastric cancer, considering the reduced risk of node metastases and local recurrence [1], LG is deemed the gold standard approach, especially in most of Eastern countries [4, 21]. This recommendation comes from the results of some randomized trials which demonstrated a lower morbidity and a non-inferior OS than the open approach [22, 23].

More recently, some Eastern studies seem to confirm that $\mathrm{LG}$ can be also considered for the treatment of AGC [24-26]. The Chinese CLASS-01 trial investigated the shortterm surgical outcomes of 1056 patients with T2-4aN0-3M0 cancer at 14 centers, reporting similar postoperative morbidity and mortality as well as severity of complications for laparoscopic and open D2 distal gastrectomy [26]. Long-term results from this trial were reported in 2019, demonstrating as non-inferior the 3-year DFS of patients assigned to the laparoscopic group than those assigned to the open group [26]. Other ongoing trials as JLSSG0901 [27] and KLASS02 [28] reported similar or lower complication rates, less postoperative pain and faster recovery for laparoscopic vs. open distal gastrectomy, while the long-term oncologic outcomes are still awaited.

It is unclear whether these findings can be applied to Western patients, who tend to have more advanced disease at presentation and a higher incidence of proximally located as well as diffuse-type cancers than Eastern patients. Furthermore, surgeon and hospital volumes of laparoscopic gastrectomy are significantly higher in the East than in the West [12]. Thus, high-quality evidence from large-scale studies on LG for AGC is lacking in Western countries, and most series include both early and advanced cancers, thus hampering a stage-based analysis [29-36].

In 2005 Huscher et al. published the only European randomized trial comparing laparoscopic and open subtotal gastrectomy for distal gastric cancer. In their analysis on 59 patients, LG was found to be a feasible and safe oncologic procedure with short- and long-term results similar or better than those of open surgery [12]. The results from the LOGICA trial [37] and the STOMACH trial [38] are still expected.

Finally, staging, surgical training and use of adjuvant therapy are different in non-tertiary referral centers [26].

For all the above reasons, well-controlled clinical studies may not reflect the actual outcome of laparoscopy for AGC in the clinical practice [8], and results from our study do 
Table 3 Logistic binary univariate and multivariate regression with postoperative complication as dependent item

\begin{tabular}{|c|c|c|c|c|c|c|}
\hline & \multicolumn{2}{|c|}{ Postoperative complications } & \multicolumn{2}{|c|}{ Univariate analysis } & \multicolumn{2}{|c|}{$\begin{array}{l}\text { Multivariate } \\
\text { analysis }\end{array}$} \\
\hline & Yes $n=100(\%)$ & No $n=266(\%)$ & OR & $p$ value & $\mathrm{aOR}$ & $p$ value \\
\hline \multicolumn{7}{|l|}{ Sex } \\
\hline $\mathrm{F}$ & $37(37 \%)$ & $125(47 \%)$ & 0.66 & 0.087 & 0.621 & 0.064 \\
\hline M & $63(63 \%)$ & $141(53 \%)$ & l & l & l & l \\
\hline Age & $69.6 \pm 12.9$ & $67.9 \pm 11.1$ & 1 & 0.209 & 1 & 0.238 \\
\hline BMI & $24.3 \pm 4.42$ & $24.96 \pm 4$ & 0.96 & 0.238 & 1 & 0.192 \\
\hline \multicolumn{7}{|l|}{ ASA } \\
\hline 3 & $33(33 \%)$ & $79(29.7 \%)$ & 1.13 & 0.5 & 1.05 & 0.8 \\
\hline 2 & $57(57 \%)$ & $155(58.3 \%)$ & l & l & l & l \\
\hline 1 & $10(10 \%)$ & $32(12 \%)$ & l & l & l & l \\
\hline Operative time & $257.7 \pm 105.2$ & $243.9 \pm 105.2$ & 1 & 0.266 & 1 & 0.26 \\
\hline \multicolumn{7}{|l|}{ Procedure } \\
\hline LTG & $33(33 \%)$ & $76(28.6 \%)$ & 0.812 & 0.4 & 1.03 & 0.9 \\
\hline LSG & $67(67 \%)$ & $190(71.4 \%)$ & l & l & l & l \\
\hline \multicolumn{7}{|l|}{ Conversion } \\
\hline Yes & & & & & 1 & 0.9 \\
\hline No & & & I & I & I & I \\
\hline Blood loss & $104 \pm 91$ & $91 \pm 68$ & & & 1 & 0.116 \\
\hline \multicolumn{7}{|c|}{ Intraop. complication } \\
\hline Yes & $7(7 \%)$ & $14(5.3 \%)$ & 0.73 & 0.52 & 0.5 & 0.62 \\
\hline No & $93(93 \%)$ & $252(94.7 \%)$ & l & l & l & l \\
\hline Harvested nodes & $25 \pm 9$ & $27 \pm 11$ & 1 & 0.13 & 1 & 0.214 \\
\hline Metastatic nodes & $3 \pm 4$ & $3 \pm 4$ & 1 & 0.821 & 1 & 0.773 \\
\hline \multicolumn{7}{|l|}{ Stage } \\
\hline III & $60(60 \%)$ & $162(60.9 \%)$ & 1.03 & 0.87 & 0.7 & 0.25 \\
\hline II & $40(40 \%)$ & $104(39.1 \%)$ & l & l & l & l \\
\hline \multicolumn{7}{|c|}{ Neoadjuvant therapy } \\
\hline Yes & $38(38 \%)$ & $59(22.2 \%)$ & 2.15 & 0.03 & 2.17 & 0.04 \\
\hline No & $62(62 \%)$ & $207(77.8 \%)$ & I & I & I & l \\
\hline
\end{tabular}

Data are reported as number of patients $(\%)$ or mean ( \pm standard deviation) or median $( \pm \mathrm{IQR})$. OR and corresponding $p$ values are obtained using logistic binary univariate and multivariate regression provide real-life data on the safety and oncologic efficacy of LG in a large series of patients from different Western institutions.

We recorded an overall postoperative morbidity of $27.3 \%$, but the majority $(66 \%)$ of complications were classified as grade II requiring only a pharmacological treatment. These results are consistent with those of most published Western series. Huscher et al. reported a morbidity rate of $26.7 \%$ following laparoscopic distal gastrectomy [12]. Also, several other retrospective studies reported an incidence of postoperative complications ranging from 25 to about $32 \%$ [29-36]. It has been suggested that the laparoscopic approach may decrease the incidence of minor complications in the early and late postoperative periods compared with the open approach [32]. In a recent study from Korea on 1483 laparoscopic gastrectomies for AGC, the overall morbidity rate was $9.1 \%$ with $54 \%$ of complications being classified as grade $\geq 3$. At the multivariate analysis, age was found to be associated with postoperative morbidity, endorsing that extended surgery, although minimally invasive, may be risky for the elderly [8]. Other predictive factors for complications have been suggested, including sex, comorbidity, type of resection and surgeon's experience [26]. Our study experience suggests that neoadjuvant therapy may lead to an increased risk of postoperative complications. Although this observation has not been confirmed by several other investigators [39-41], the analysis of the CRITICS gastric cancer trial revealed a morbidity rate as high as $47 \%$ in patients receiving neoadjuvant chemotherapy [42]. On the other hand, it has been suggested that preoperative chemotherapy may abolish the poor prognosis induced by postoperative complications after curative resection [43].

We reported a $14.5 \%$ conversion rate. However, 40 conversions were recorded during the first ten years of 

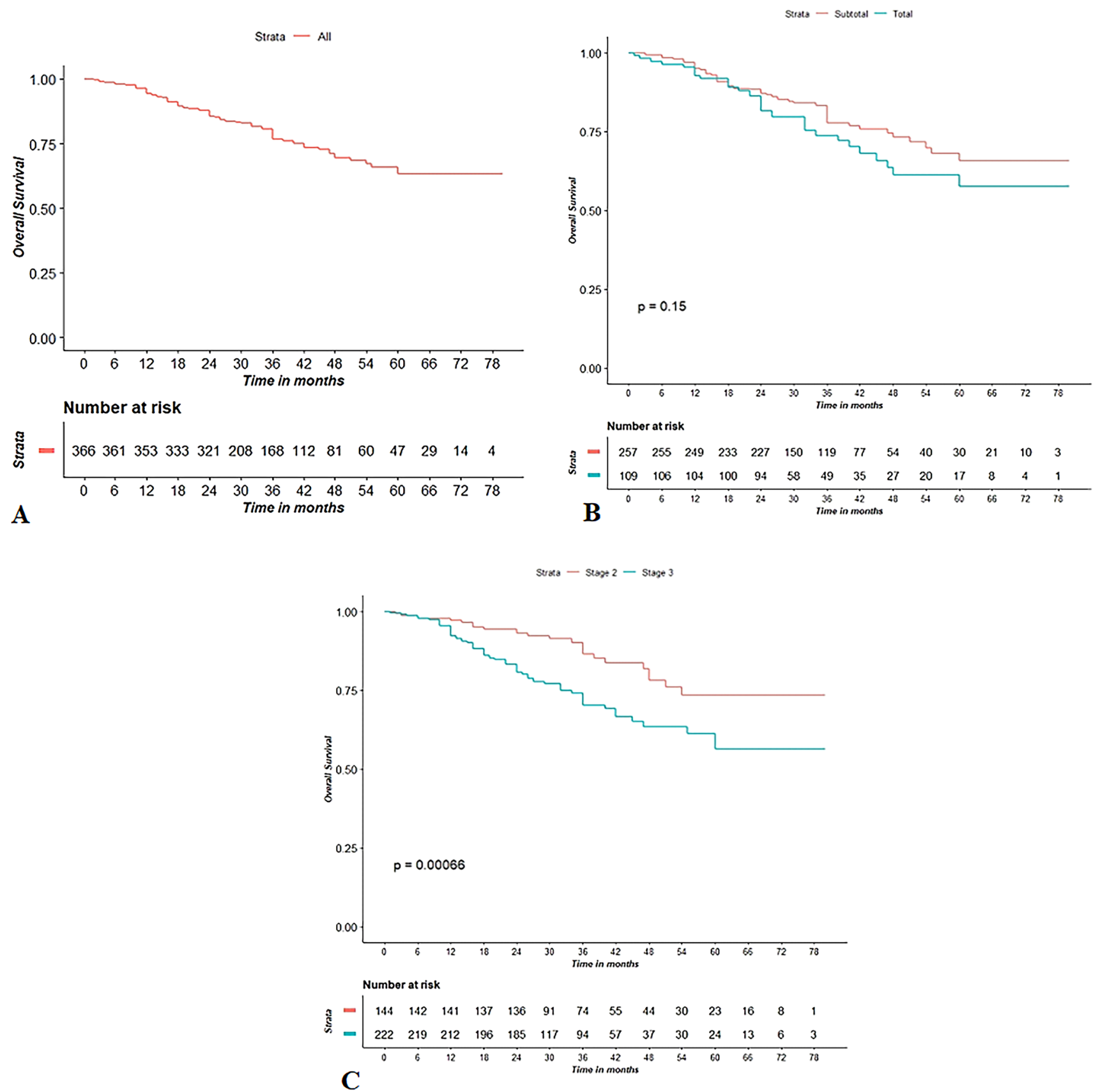

Fig. 1 Kaplan-Meier curve for OS (A); Kaplan-Meier curve for OS, stratifying for procedure (B) and stage (C)

the study period while, over the last five years, the rate decreased to $3.6 \%$ which favorably compares to that of some previous reports, ranging from 2.2 to $7 \%$ [11, 44-46]. Also, a conversion rate up to $17.4 \%$ has been reported following LTG in large series [47]. Our finding is probably related to the improved technical skills and experience of the surgeons over the study period as well as to prompt consideration of conversion when concerned for adequate oncologic resection [32]. The most common reason for conversion was a technical factor such as adhesions, bleeding during difficult lymphadenectomy, whereas tumor factors (bulky/T4) accounted for about $23 \%$ of conversions.

All procedures started with a DL in order to detect a possible carcinomatosis. DL represents the first step during LG. It plays an important role in avoiding unnecessary laparotomies, particularly in cases of AGC. Many studies showed that DL demonstrated moderate to substantial agreement with final pathology for $\mathrm{T}$ stage, but only fair agreement for $\mathrm{N}$ stage. For M staging, DL had an overall 
Table 4 Cox regression model analysis for overall survival (OS)

\begin{tabular}{|c|c|c|c|c|c|c|}
\hline & \multicolumn{2}{|l|}{ Death } & \multicolumn{2}{|c|}{ Univariate analysis } & \multicolumn{2}{|c|}{$\begin{array}{l}\text { Multivariate } \\
\text { analysis }\end{array}$} \\
\hline & Yes $(n=90)$ & No $(n=276)$ & HR & $p$ value & $\mathrm{a}-\mathrm{HR}$ & $p$ value \\
\hline \multicolumn{7}{|l|}{ Procedure } \\
\hline LTG & $35(38.9 \%)$ & $74(26.8 \%)$ & 1.36 & 0.15 & 1.24 & 0.34 \\
\hline LSG & $55(61.1 \%)$ & $202(73.2 \%)$ & I & l & I & l \\
\hline \multicolumn{7}{|l|}{ Conversion } \\
\hline Yes & $20(22.2 \%)$ & $33(12 \%)$ & 1.37 & 0.349 & 1.27 & 0.38 \\
\hline No & $70(77.8 \%)$ & $243(88 \%)$ & l & l & I & / \\
\hline Harvested nodes & $26.2 \pm 11.0$ & $26.9 \pm 10.77$ & 1 & 0.75 & 1 & 0.74 \\
\hline Metastatic nodes & $4.99 \pm 5.13$ & $2.53 \pm 3.84$ & 1.1 & $<0.001$ & 1.06 & 0.009 \\
\hline \multicolumn{7}{|l|}{ Stage } \\
\hline III & $66(73.3 \%)$ & $156(56.5 \%)$ & 2.2 & 0.001 & 1.5 & 0.15 \\
\hline II & $24(26.7 \%)$ & $120(43.5)$ & l & l & I & l \\
\hline \multicolumn{7}{|c|}{ Neoadjuvant therapy } \\
\hline Yes & $29(32.2 \%)$ & $68(24.6 \%)$ & 1.4 & 0.09 & 1.2 & 0.44 \\
\hline No & $61(67.8 \%)$ & $208(75.4)$ & I & I & I & I \\
\hline
\end{tabular}

Data are reported as number of patients $(\%)$ or mean ( \pm standard deviation). HR and corresponding $p$ values are obtained using Cox regression analysis accuracy, sensitivity, and specificity ranging from 85-98.9\%, 64.3-94\%, and 80-100\%, respectively [18].

D2 lymph node dissection is of paramount importance for curative gastrectomy, but due to the technical difficulties it has limited enthusiasm for laparoscopic approach to AGC [33]. Concern about achieving adequate lymph node retrieval has been raised in some earlier series, where up to $38 \%$ of patients had less than the AJCC minimum number of lymph node harvest needed for proper staging [48]. In our experience, the mean number of 25 harvested nodes allowed us to meet the criteria for adequate laparoscopic lymphadenectomy in AGC [12]. Since early 2000s, there have been many controversies on the performance of splenectomy, and the prognostic value of lymphadenectomy of the n.10 station is debated [1]. In accordance with the SIC-GIRCG 2013 Consensus Conference on Gastric Cancer, radical excision of the splenic hilum lymph nodes or splenectomy was reserved for AGC cases of the upper greater curvature, in which the malignancy was suspected to be T4 or there were suspected nodes at splenic hilum [16]. Similarly, according to the most recent Japanese guidelines, dissection of $n .10$ nodes/splenectomy is excluded from standard D2 dissection, unless a tumor of the upper stomach invades the greater curvature or there are metastases to no. 4sb lymph nodes [4]. In those cases, we believe that the open approach should be preferred [12].

In our series, the OS probability was 0.94 at 1 year and 0.63 at 5 years, while the DFS probability was 0.85 at 1 year and 0.62 at 5 years. These figures favorably compare to those of the few Western studies which analyzed survival data. In their series of 30 laparoscopic cases with $57 \%$ of stage $\geq$ II cancers, Huscher et al. found 5-year OS and DFS rates of $58.9 \%$ and $57.3 \%$, respectively [12]. Similar results have been reported in a series of 70 AGC (stage IB-IV) patients undergoing laparoscopic gastrectomy [12]. Kelly et al. reported higher rates of $81 \%$ and $85 \%$ in their cohort of 87 patients; however, only $37 \%$ of tumors were stage II and III [12]. Three-year survival data have been analyzed in a series of 21 AGC patients, with an OS of $69.5 \%$ and a relapse-free survival of $44.5 \%$ [48]. At 5 years, we found an OS probability of 0.73 for stage II and 0.56 for stage III. Survival data for cancer stage are mainly available Eastern studies. In their retrospective analysis of a 15-year experience, Min et al. reported a 5-year OS of $88.7 \%$ for stage IIA, 84.2 for stage IIB and $60.3 \%$ for stage III, with a significant difference between stages IIIA, IIIB and IIIC [8].

We reported an overall recurrence rate of $28.6 \%$, which is in the range of $13.3 \%$ to $50 \%$ reported by other authors [29-36, 48, 49]. Peritoneal involvement has been reported as the most common type of recurrence after LG in several Eastern series [50], while recurrence patterns in Western patients have not been well established [48]. In our study, the most common sites of recurrence were peritoneum $(7.1 \%)$, liver $(5.7 \%)$ and regional lymph nodes (4\%). Similarly, in a series of 21 patients, the recurrence rate was $38.1 \%$ $(8 / 21)$; peritoneal recurrence was recorded in $19 \%(4 / 21)$, distant recurrence in $14.3 \%(3 / 21)$ and a mixed pattern (both locoregional and distant) in $4.8 \%(1 / 21)$ [48]. Strong et al. [36] found an equal distribution of local $(n=2,6.6 \%)$ and distant $(n=2,6.6 \%)$ recurrence in a cohort of 30 patients. Sica et al. [49] reported 11 cases $(11 / 22,50 \%)$ of recurrence after a median follow-up of 39 months, with hepatic 

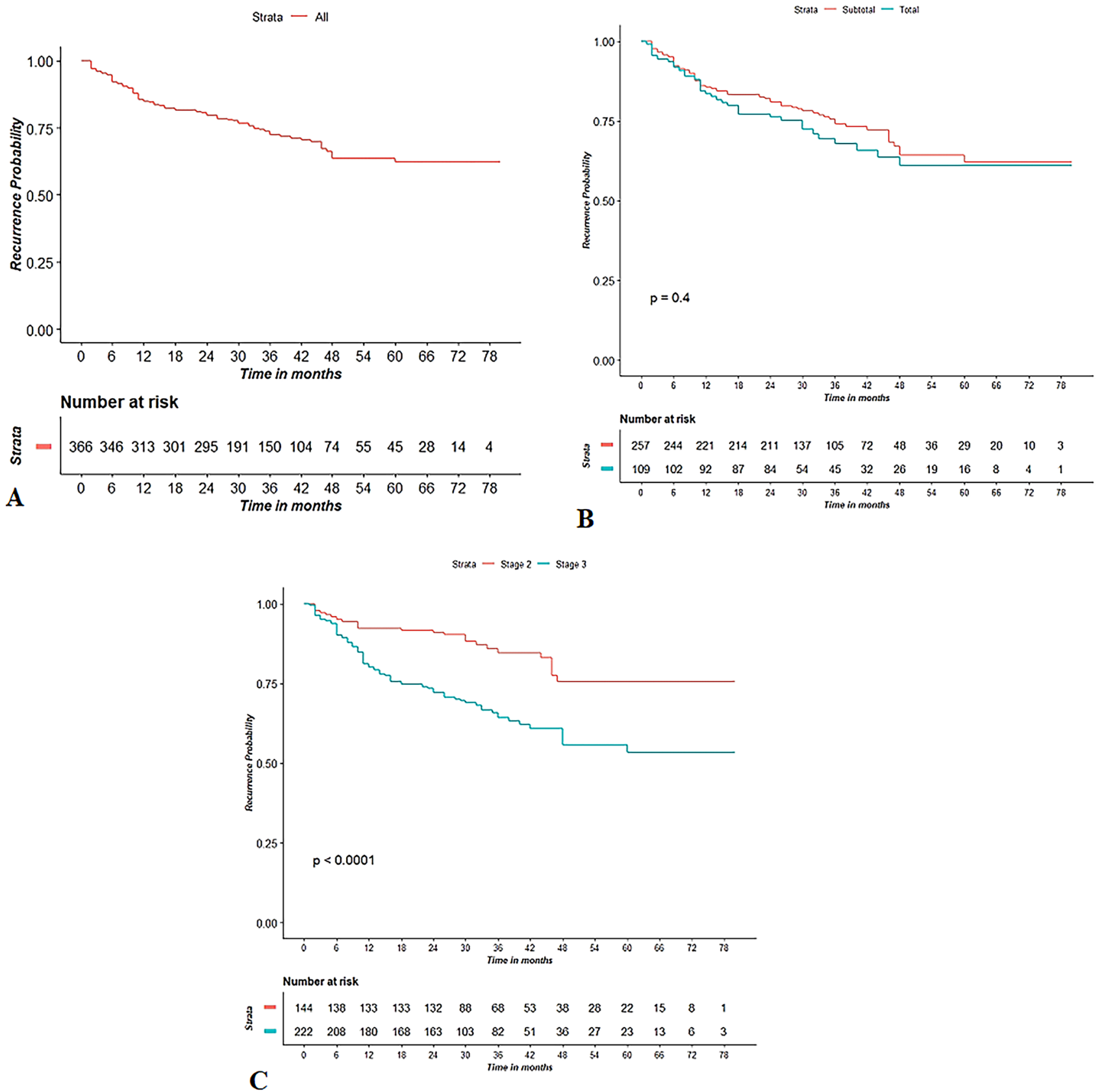

Fig. 2 Kaplan-Meier curve for DFS (A); Kaplan-Meier curve for DSF, stratifying for procedure (B) and stage (C)

metastases being the most common $(6 / 22,27.3 \%)$, followed by other distant recurrences $(3 / 22,13.7 \%)$ and locoregional recurrence $(2 / 22,9 \%)$. Some authors argue that while distant metastases after LG can be explained by invisible micrometastasis during or before surgery, local recurrence may be associated with the adequacy of surgery [8].

Many doubts still concern the role of neoadjuvant chemotherapy for gastric cancer [50-52].

In the present study, neoadjuvant chemotherapy is not associated with recurrence or death. This finding is consistent with the EORTC trial [53] that failed to demonstrate prognostic benefits regarding OS after neoadjuvant chemotherapy, despite a significantly increased R0 resection rate. Furthermore, only $26 \%$ of patients in our series received neoadjuvant treatment. Finally we argue that a quality of surgery with adeguate lymphadenectomy performed by experienced surgeons could minimize the risk of metastatic nodes.

Our study has some limitations mainly related to the retrospective design. Data have been collected from 
Table 5 Cox regression model analysis for disease-free survival (DFS)

\begin{tabular}{|c|c|c|c|c|c|c|}
\hline & \multicolumn{2}{|l|}{ Recurrence } & \multicolumn{2}{|c|}{ Univariate analysis } & \multicolumn{2}{|c|}{$\begin{array}{l}\text { Multivariate } \\
\text { analysis }\end{array}$} \\
\hline & Yes $n=105(\%)$ & No $n=261(\%)$ & $\mathrm{HR}$ & $p$ value & $\mathrm{a}-\mathrm{HR}$ & $p$ value \\
\hline \multicolumn{7}{|l|}{ Procedure } \\
\hline LTG & $35(33.3 \%)$ & $74(28.3 \%)$ & 1.2 & 0.4 & 1 & 0.75 \\
\hline LSG & $70(67.7 \%)$ & $187(71.7 \%)$ & l & I & l & I \\
\hline \multicolumn{7}{|l|}{ Conversion } \\
\hline Yes & $24(22.8 \%)$ & $29(11.11 \%)$ & 1.9 & 0.003 & 1.3 & 0.26 \\
\hline No & $81(77.2 \%)$ & $232(88.9 \%)$ & l & l & l & l \\
\hline Harvested nodes & $26 \pm 11$ & $27 \pm 11$ & 1 & 0.76 & 1 & 0.74 \\
\hline Metastatic nodes & $5 \pm 5$ & $2 \pm 4$ & 1.1 & $<0.001$ & 1.06 & 0.003 \\
\hline \multicolumn{7}{|l|}{ Stage } \\
\hline III & $81(77.2 \%)$ & $141(54 \%)$ & 2.5 & $<0.001$ & 1.75 & 0.037 \\
\hline II & $24(22.8 \%)$ & $120(46 \%)$ & l & l & l & l \\
\hline \multicolumn{7}{|c|}{ Neoadjuvant therapy } \\
\hline Yes & $33(31.4 \%)$ & $64(24.5 \%)$ & 1.3 & 0.2 & 1 & 0.8 \\
\hline No & $72(68.6 \%)$ & $197(75.5 \%)$ & l & I & I & I \\
\hline
\end{tabular}

Data are reported as number of patients $(\%)$ or mean ( \pm standard deviation). HR and corresponding $p$ values are obtained using Cox regression analysis different institutions over a 15 -year period. Thus, treatment protocols and perioperative management were not standardized. No patients received neoadjuvant therapy until 2010, which can influence postoperative outcomes. Moreover, there has been much development of procedures and technologies over time, and this does influence the data. Also, although proficiency of participating surgeons has been established, their experience and technical skill increased as time passed. However, these limitations are inherent in that the study provides a true representation of outcomes in a general practice setting.

In conclusion, our study has led us to conclude that laparoscopic gastrectomy for advanced gastric cancer is feasible and safe in the general practice of Western institutions when performed by trained surgeons. Similarly, some caution must be exercised when translating the current evidence also on Robotic Assisted Gastrectomy (RAG) to a European population. Benefits of RAG include the use of ICG to assess vascularity and (sentinel) lymph nodes. Inclusion of artificial intelligence and machine learning to aid the surgeon in these complex procedures are coming on the horizon [54].

Randomized controlled trials carried out in this setting are needed to corroborate our results.

Funding Open access funding provided by Università degli Studi di Napoli Federico II within the CRUI-CARE Agreement. The authors declare no sources of funding received for the article submitted to the journal.

\section{Declarations}

Disclosures Drs. Umberto Bracale, Giovanni Merola, Giusto Pignata, Jacopo Andreuccetti, Pasquale Dolce, Luigi Boni, Elisa Cassinotti, Stefano Olmi, Matteo Uccelli, Monica Gualtierotti, Giovanni Ferrari, Paolo De Martini, Miloš Bjelović, Dragan Gunjić, Vania Silvestri, Emanuele Pontecorvi, Roberto Peltrini, Felice Pirozzi, Diego Cuccurullo, Antonio Sciuto and Francesco Corcione have no conclicts of interest or financial ties to disclosure.

Open Access This article is licensed under a Creative Commons Attribution 4.0 International License, which permits use, sharing, adaptation, distribution and reproduction in any medium or format, as long as you give appropriate credit to the original author(s) and the source, provide a link to the Creative Commons licence, and indicate if changes were made. The images or other third party material in this article are included in the article's Creative Commons licence, unless indicated otherwise in a credit line to the material. If material is not included in the article's Creative Commons licence and your intended use is not permitted by statutory regulation or exceeds the permitted use, you will need to obtain permission directly from the copyright holder. To view a copy of this licence, visit http://creativecommons.org/licenses/by/4.0/. 


\section{References}

1. Agnes A, Biondi A, Laurino A et al (2020) Global updates in the treatment of gastric cancer: a systematic review. Part 1: staging, classification and surgical treatment. Updates Surg 72(2):341353. https://doi.org/10.1007/s13304-020-00736-3

2. Pan Y, Chen K, Yu WH et al (2018) Laparoscopic gastrectomy for elderly patients with gastric cancer: a systematic review with meta-analysis. Medicine 97(8): $\mathrm{e} 0007$

3. Smyth EC, Verheij M, Allum W et al (2016) Gastric cancer: ESMO Clinical Practice Guidelines for diagnosis, treatment and follow-up. Ann Oncol 27(suppl 5):v38-v49

4. Japanese Gastric Cancer A (2020) Japanese gastric cancer treatment guidelines 2018, 5th edn. Gastric Cancer

5. Kitano S, Iso Y, Moriyama M et al (1994) Laparoscopy-assisted Billroth I gastrectomy. Surg Laparosc Endosc 4(2):146-148

6. Bracale U, Lazzara F, Merola G et al (2013) Single access laparoscopic left hemicolectomy with or without inferior mesenteric artery preservation: our preliminary experience. Minerva Chir 68(3):315-320

7. Coccolini F, Montori G, Ceresoli M et al (2016) Advanced gastric cancer: what we know and what we still have to learn. World J Gastroenterol 22(3):1139-1159

8. Min SH, Won Y, Kim G et al (2019) 15-year experience of laparoscopic gastrectomy in advanced gastric cancer: analysis on short-term and long-term oncologic outcome. Surg Endosc. https://doi.org/10.1007/s00464-019-07292-x

9. Hamabe A, Omori T, Tanaka K et al (2012) Comparison of long-term results between laparoscopy-assisted gastrectomy and open gastrectomy with D2 lymph node dissection for advanced gastric cancer. Surg Endosc 26(6):1702-1709

10. Shinohara T, Satoh S, Kanaya S et al (2013) Laparoscopic versus open D2 gastrectomy for advanced gastric cancer: a retrospective cohort study. Surg Endosc 27(1):286-294

11. Kim KH, Kim MC, Jung GJ et al (2012) Comparative analysis of five-year survival results of laparoscopy-assisted gastrectomy versus open gastrectomy for advanced gastric cancer: a case-control study using a propensity score method. Dig Surg 29(2):165-171

12. Huscher CG, Mingoli A, Sgarzini G et al (2005) Laparoscopic versus open subtotal gastrectomy for distal gastric cancer: five-year results of a randomized prospective trial. Ann Surg 241(2):232-237

13. Son T, Sun J, Choi S et al (2019) Multi-institutional validation of the 8th AJCC TNM staging system for gastric cancer: analysis of survival data from high-volume Eastern centers and the SEER database. J Surg Oncol 120(4):676-684

14. Clavien PA, Barkun J, de Oliveira ML et al (2009) The ClavienDindo classification of surgical complications: five-year experience. Ann Surg 250(2):187-196

15. Kim SH, Son SY, Park YS et al (2015) Risk factors for anastomotic leakage: a retrospective cohort study in a single gastric surgical unit. J Gastric Cancer 15(3):167-175

16. De Manzoni G, Baiocchi GL, Framarini M et al (2014) The SICGIRCG 2013 consensus conference on gastric cancer. Updates Surg 66(1):1-6

17. Corcione F, Pirozzi F, Cuccurullo D et al (2013) Laparoscopic total gastrectomy in gastric cancer: our experience in 92 cases. Minim Invasive Ther Allied Technol 22(5):271-278

18. Bracale U, Pignata G, Lirici MM et al (2012) Laparoscopic gastrectomies for cancer: the ACOI-IHTSC national guidelines. Minim Invasive Ther Allied Technol 21(5):313-319

19. Bracale U, Marzano E, Nastro P et al (2010) Side-to-side esophagojejunostomy during totally laparoscopic total gastrectomy for malignant disease: a multicenter study. Surg Endosc 24(10):2475-2479

20. Knight BC, Rice SJ, Devitt PG et al (2014) Proximal anastomosis using the OrVil circular stapler in major upper gastrointestinal surgery. J Gastrointest Surg 18(7):1345-1349

21. Guideline Committee of the Korean Gastric Cancer Association DWG, Review P (2019) Korean practice guideline for gastric cancer 2018: an evidence-based, Multi-disciplinary Approach. J Gastric Cancer 19(1):1-48

22. Kim HH, Han SU, Kim MC et al (2019) Effect of laparoscopic distal gastrectomy vs open distal gastrectomy on long-term survival among patients with stage I gastric cancer: the KLASS-01 Randomized Clinical Trial. JAMA Oncol 5(4):506-513

23. Katai H, Mizusawa J, Katayama H et al (2017) Short-term surgical outcomes from a phase III study of laparoscopy-assisted versus open distal gastrectomy with nodal dissection for clinical stage IA/IB gastric cancer: Japan Clinical Oncology Group Study JCOG0912. Gastric Cancer 20(4):699-708

24. Li Z, Shan F, Ying X et al (2019) Assessment of laparoscopic distal gastrectomy after neoadjuvant chemotherapy for locally advanced gastric cancer: a randomized clinical trial. JAMA Surg 154(12):1093-1101. https://doi.org/10.1001/jamasurg.2019.3473

25. Hu Y, Huang C, Sun Y et al (2016) Morbidity and mortality of laparoscopic versus open D2 distal gastrectomy for advanced gastric cancer: a randomized controlled trial. J Clin Oncol 34(12):1350-1357

26. Yu J, Huang C, Sun Y et al (2019) Effect of laparoscopic vs open distal gastrectomy on 3-year disease-free survival in patients with locally advanced gastric cancer: the CLASS-01 randomized clinical trial. JAMA 321(20):1983-1992

27. Lee S-W, Etoh T, Ohyama T et al (2017) Short-term outcomes from a multi-institutional, phase III study of laparoscopic versus open distal gastrectomy with D2 lymph node dissection for locally advanced gastric cancer (JLSSG0901). J Clin Oncol 35(15):4029-4029

28. Lee HJ, Hyung WJ, Yang HK et al (2019) Short-term outcomes of a multicenter randomized controlled trial comparing laparoscopic distal gastrectomy with D2 lymphadenectomy to open distal gastrectomy for locally advanced gastric cancer (KLASS02-RCT). Ann Surg 270(6):983-991

29. Kelly KJ, Selby L, Chou JF et al (2015) Laparoscopic versus open gastrectomy for gastric adenocarcinoma in the west: a case-control study. Ann Surg Oncol 22(11):3590-3596

30. Tuttle R, Hochwald SN, Kukar M et al (2016) Total laparoscopic resection for advanced gastric cancer is safe and feasible in the Western population. Surg Endosc 30(8):3552-3558

31. Varela JE, Hiyashi M, Nguyen T et al (2006) Comparison of laparoscopic and open gastrectomy for gastric cancer. Am J Surg 192(6):837-842

32. Kachikwu EL, Trisal V, Kim J et al (2011) Minimally invasive total gastrectomy for gastric cancer: a pilot series. J Gastrointest Surg 15(1):81-86

33. Guzman EA, Pigazzi A, Lee B et al (2009) Totally laparoscopic gastric resection with extended lymphadenectomy for gastric adenocarcinoma. Ann Surg Oncol 16(8):2218-2223

34. Huscher CG, Mingoli A, Sgarzini G et al (2004) Videolaparoscopic total and subtotal gastrectomy with extended lymph node dissection for gastric cancer. Am J Surg 188(6):728-735

35. Martinez-Ramos D, Miralles-Tena JM, Cuesta MA et al (2011) Laparoscopy versus open surgery for advanced and resectable gastric cancer: a meta-analysis. Rev Esp Enferm Dig 103(3):133-141

36. Strong VE, Devaud N, Allen PJ et al (2009) Laparoscopic versus open subtotal gastrectomy for adenocarcinoma: a case-control study. Ann Surg Oncol 16(6):1507-1513 
37. Haverkamp L, Brenkman HJF, Seesing MFJ et al (2015) Laparoscopic versus open gastrectomy for gastric cancer, a multicenter prospectively randomized controlled trial (LOGICA-trial). BMC Cancer 15(1):556

38. Straatman J, van der Wielen N, Cuesta MA et al (2015) Surgical techniques, open versus minimally invasive gastrectomy after chemotherapy (STOMACH trial): study protocol for a randomized controlled trial. Trials 16:123

39. Haskins IN, Kroh MD, Amdur RL et al (2017) The effect of neoadjuvant chemoradiation on anastomotic leak and additional 30-day morbidity and mortality in patients undergoing total gastrectomy for gastric cancer. J Gastrointest Surg 21(10): 1577-1583

40. Fuentes E, Ahmad R, Hong TS et al (2016) The impact of neoadjuvant therapy for gastroesophageal adenocarcinoma on postoperative morbidity and mortality. J Surg Oncol 113(5):560-564

41. Badgwell B, Ajani J, Blum M et al (2016) Postoperative morbidity and mortality rates are not increased for patients with gastric and gastroesophageal cancer who undergo preoperative chemoradiation therapy. Ann Surg Oncol 23(1):156-162

42. Claassen YHM, Hartgrink HH, Dikken JL et al (2018) Surgical morbidity and mortality after neoadjuvant chemotherapy in the CRITICS gastric cancer trial. Eur J Surg Oncol 44(5):613-619

43. Eto K, Hiki N, Kumagai K et al (2018) Prophylactic effect of neoadjuvant chemotherapy in gastric cancer patients with postoperative complications. Gastric Cancer 21(4):703-709

44. Park DJ, Lee HJ, Kim HH et al (2005) Predictors of operative morbidity and mortality in gastric cancer surgery. Br J Surg 92(9):1099-1102

45. Lee J, Kim W (2009) Long-term outcomes after laparoscopyassisted gastrectomy for advanced gastric cancer: analysis of consecutive 106 experiences. J Surg Oncol 100(8):693-698

46. Lee JH, Son SY, Lee CM et al (2013) Morbidity and mortality after laparoscopic gastrectomy for advanced gastric cancer: results of a phase II clinical trial. Surg Endosc 27(8):2877-2885
47. Ye M, Jin K, Xu G et al (2017) Short- and long-term outcomes after conversion of laparoscopic total gastrectomy for gastric cancer: a single-center study. J BUON 22(1):126-133

48. MacLellan SJ, MacKay HJ, Ringash J et al (2012) Laparoscopic gastrectomy for patients with advanced gastric cancer produces oncologic outcomes similar to those for open resection. Surg Endosc 26(7):1813-1821

49. Sica GS, Iaculli E, Biancone L et al (2011) Comparative study of laparoscopic vs open gastrectomy in gastric cancer management. World J Gastroenterol 17(41):4602-4606

50. Kinoshita T, Uyama I, Terashima M et al (2019) Long-term outcomes of laparoscopic versus open surgery for clinical stage II/ III gastric cancer: a Multicenter Cohort Study in Japan (LOC-A Study). Ann Surg 269(5):887-894

51. Rausei S, Bali CD, Lianos GD (2020) Neoadjuvant chemotherapy for gastric cancer. Has the time to decelerate the enthusiasm passed us by? Semin Oncol. 47(6):355-360. https://doi.org/10. 1053/j.seminoncol.2020.07.003 (Epub 2020 Jul 25)

52. Reddavid R, Sofia S, Chiaro P et al (2018) Neoadjuvant chemotherapy for gastric cancer, Is it a must or a fake? World J Gastroenterol 24(2):274-289

53. Schuhmacher C, Gretschel S, Lordick F et al (2010) Neoadjuvant chemotherapy com- 188 pared with surgery alone for locally advanced cancer of the stomach and car- 189 dia: EORTC randomized trial 40954. J Clin Oncol 28:5210-5218

54. Van Boxel GI, Ruurda JP, van Hillegersberg R (2019) Roboticassisted gastrectomy for gastric cancer: a European perspective. Gastric Cancer 22(5):909-919. https://doi.org/10.1007/s10120019-00979-z (Epub 2019 Jul 4)

Publisher's Note Springer Nature remains neutral with regard to jurisdictional claims in published maps and institutional affiliations. 